\title{
Derecho de la Libre Competencia
}

Fernando Araya Jasma

Profesor de Derecho Comercial

Universidad Diego Portales
"Efectos Paraguas" de la colusión y LA IMPUTACIÓN OBJETIVA DE LOS DAÑOS INDEMNIZABLES: SENTENCIA DEL TRIBUNAL DE Justicia de la Unión Europea (SAla Quinta), 5 de Junio de 2014, ASUNTO C-557/12

\section{LA MIRADA AL DERECHO EXTRANJERO EN EL CONTEXTO ACTUAL}

Son pocas las áreas del Derecho que, en el mundo de hoy, pueden librarse del todo de las influencias del Derecho extranjero. Muy por el contrario, el derecho de la libre competencia en Chile se ha desarrollado teniendo a la vista la evolución de la disciplina en jurisdicciones de más antigua tradición como la estadounidense y la europea ${ }^{1}$, y se han incorporado aquí, mutatis mutandi y con algo de rezago, algunas

${ }^{1}$ Sólo por mostrar un ejemplo reciente, sentencia del TC, 9 de octubre de 2012, rol 2658-14-INA sobre inaplicabilidad por inconstitucionalidad de la letra c) del artículo 26 del DL No 211, donde, en su punto sexto de 'antecedentes', para fundamentar a favor de una concepción flexible sobre los múltiples factores que permiten enjuiciar los acuerdos entre empresas que tengan por objeto o por efecto restringir la libre competencia, el TC reproduce los razonamientos de la sentencia del TJUE de 13 de diciembre de 2012 en el asunto C-226/11, "que cita abundante jurisprudencia anterior". de las instituciones extranjeras mejor asentadas.

Quizá la circunstancia mencionada justifique por sí sola dedicar estos comentarios, de tiempo en tiempo, a los hitos jurisprudenciales que tienen lugar en jurisdicciones foráneas. Pero la verdad es que la materia sobre la que recae la sentencia comentada, por una parte, y la presentación por el gobierno en Chile de un proyecto de reforma legislativa que apunta a mejorar la institucionalidad de libre competencia, entre otros, en las áreas de la represión contra la colusión entre competidores ${ }^{2}$, por la otra, fueron motivos adicionales para desviar la mirada, en esta ocasión, hacia Luxemburgo.

\section{Daños a las víctimas EN LOS CASOS DE COLUSIÓN}

Lo que se conoce como el private enforcement o aplicación del derecho de la competencia por impulso de particulares, por oposición al public enforcement o aplicación del derecho de la competencia por la autoridad administrativa

${ }^{2}$ A la fecha de cierre de la edición de este comentario (10 de octubre de 2014), el gobierno no ha hecho público el contenido del proyecto anunciado, pero pudimos compartir algunas de estas notas con uno de sus redactores. 
no ha sido objeto de acalorados debates en Chile. Y, si bien la discusión poco a poco comienza a instalarse entre los autores nacionales ${ }^{3}$, a menos que se proponga la introducción de cambios legislativos importantes en el área, nos mantendremos -para bien dirán algunos- muy lejos de la situación en Estados Unidos donde, de cada diez casos antimonopolios federales iniciados por particulares, hay uno que inician la FTC o el DOJ ${ }^{4}$.

Sin una propuesta legislativa osada, tampoco nos encontraremos con una discusión de largo aliento como la que la DG Comp de la CE ha impulsado desde el año 2005 cuando se lanzó el Green Paper sobre acciones indemnizatorias por incumplimiento de las reglas del Derecho Europeo de la competencia, y que se ha traducido, en abril de 2014, en la aprobación porel Parlamento Europeo de la propuesta de la CE para una directiva sobre demandas por daños y perjuicios por infracciones a las disposiciones del Derecho de la competencia de los Estados miembros y de la Unión Europea, instrumento normativo que busca incrementar la disuasión de las prácticas colusorias y facilitar la compensación del interés de las víctimas afectadas por este tipo de ilícitos ${ }^{5}$.

${ }^{3}$ Entre otros, Banfi (2014), Banfi (2013), Lewin (2011), Montt \&Mordoj (2010), Araya (2005). Cabe destacar también que el Centro de Libre Competencia UC haya dedicado su VIII Jornada de Libre Competencia, el 25 de octubre de 2013, al tema "Responsabilidad Civil y Libre Competencia", con la participación de destacados expositores.

${ }^{4}$ Crane (2010), p. 676. Si bien, en este $90 \%$ de casos privados, no todos son casos antimonopolios en sentido estricto.

${ }^{5}$ Puede revisarse abundante información sobre este largo proceso en http://ec.europa.
Es que la idea de un "procurador privado del interés público" que inspiró en Estados Unidos el establecimiento en la Ley Sherman de Competencia de 1890 por medio de establecer

"daños triplicados para las víctimas y un honorario razonable para los abogados" ${ }^{6}$,

después de un siglo de evolución de dicho sistema, sigue insertándose con dificultad en los sistemas de Derecho Continental donde, consecuentemente, se ha terminado privilegiando el public enforcement.

Mantener un estado de situación semejante tampoco debiera ampararse en los supuestos excesos que el private enforcement del Derecho antimonopolios ha acarreado al sistema estadounidense. Esta crítica frecuente a dicho sistema ha sido desvirtuada por los profesores Joshua Davis y Robert Lande. En un reciente estudio, los autores sostienen que el private enforcement podría ser un disuasivo de conductas anticompetitivas incluso más potente que el exitoso programa anticolusión del $\mathrm{DOJ}^{7}$. Así, por ejemplo, calculan que entre 1990 y 2011, la disuasión total asociada a casos de colusión liderados por el DOJ alcanzó once mil setecientos millones de dólares, mientras que el total ob-

eu/competition/antitrust/actionsdamages/ documents.html

6 "Por la vía de ofrecer a potenciales litigantes la posibilidad de recuperar tres veces el monto de sus daños, el Congreso incentivó a estas personas a servir como 'procuradores generales privados", Corte Suprema de Estados Unidos, Hawaii v. Standard Oil Co., 405 U.S. 251 (1972), en 262 (traducción libre del autor).

${ }^{7}$ Davis \& Lande (2013), p. 26. 
tenido en sesenta casos privados en el mismo período llegó a los treinta cuatro mil- treinta y seis mil millones de dólares ${ }^{8}$. El estudio indica también que no es efectivo que las acciones privadas de daños siempre se presenten a continuación y en dependencia de las actuaciones gubernamentales de aplicación de la ley ('follow-onactions', en la jerga): de los sesenta casos que estudian, veinticuatro no habían sido precedidos por acciones del gobierno y doce se habían referido a una materia sustancialmente diferente a la de la acción del procurador público ${ }^{9}$.

Reformas al private enforcement en casos de colusión en Chile implicarían mucho más que la declaración del derecho de las víctimas a ser indemnizadas y las ventajas relativas que al efecto brinda hoy el art. $30 \mathrm{DL} \mathrm{N}^{\circ}$ 211. Mediante una reforma semejante se debiera buscar introducir mecanismos para reducir la brecha entre los poderes de la autoridad pública y las facultades de los privados para que estos últimos puedan transformarse en efectivos 'procuradores privados del interés público'. Algunas ideas referiremos al cerrar este comentario y confiamos en que el proyecto de reforma sea osado e innovador en este aspecto también.

De lo contrario, sin mecanismos adecuados, se mantendrá la paradoja que, a la autoridad encargada de velar por la competencia, esto es, a la FNE,

${ }^{8}$ Davis \& Lande (2013), p. 26, n. 110. Los autores entienden, en todo caso, que dado que algunos de los casos privados fueron subsecuentes a acciones públicas de aplicación, una parte de esa disuasión conseguida por mecanismos privados debe ser atribuida a la investigación pública inicial.

${ }^{9}$ Op. cit., p. 30. nadie está en condiciones de competirle en la detección de casos de colusión y, la experiencia comparada parece mostrar que un diseño institucional que asigna un monopolio semejante, no es aconsejable ${ }^{10} \mathrm{y}$ existe entonces

${ }^{10} \mathrm{El}$ tema se inserta en el más amplio de la descentralización vs. centralización en la aplicación del Derecho de la Competencia. Tanto el sistema estadounidense como el sistema europeo de Derecho de la Competencia presentan hoy importantes grados de descentralización en su aplicación. Primero, en cuanto a mecanismos públicos de aplicación, desde el siglo XIX el sistema estadounidense ha descansado en encargados de la aplicación en el ámbito federal (DOJ y FTC) y en el ámbito estadual (procuradores generales de los Estados) y, el sistema europeo, desde el año 2004 con la entrada en vigencia del reglamento (CE) $\mathrm{N}^{\mathrm{O}} 1 / 2003$, ha otorgado a las autoridades de competencia de los Estados miembros, y a sus órganos jurisdiccionales, atribuciones de aplicación directa del Derecho europeo de la competencia. Segundo, en cuanto a mecanismos privados, su importante función en la aplicación del Derecho estadounidense federal y estadual, con el sistema de "daños triplicados y un honorario razonable para el abogado" viene también desde el siglo XIX, junto con otros institutos como las quitam actions y las acciones colectivas. La activa promoción de mecanismos privados de aplicación en Europa, en cambio, es una cuestión promovida tan solo en los últimos diez años. En Chile, con la desaparición de los fiscales económicos regionales y las comisiones preventivas regionales, con la ley $\mathrm{N}^{\mathrm{o}} 19.911 / 2003$, los mecanismos públicos de aplicación se han centralizado (la posibilidad de designar 'fiscales adjuntos' para casos específicos y un convenio entre la FNE y el SERNAC, organismo con mayor presencia regional aparecen como sucedáneos de la presencia de la institucionalidad pública antimonopolios en regiones). Y sobre mecanismos privados, hay bastante poco: a la inclusión del hoy art. 30 DL No 211 por la ley No 19.911/ 2003, algunos casos aislados en tribunales civiles promovidos por competidores y una acción colectiva subsecuente al 'caso farmacias' en actual tramitación promovida por el SERNAC, pueden agregarse recientes declaraciones de prensa del Fiscal Nacional Económico que frente al caso de 'colusión de los pollos' ha expresado que la FNE espera que las víctimas demanden 
un importante espacio para conjuga rmejor public y privatee nforcement.

La sentencia que comentamos constituye un hito más en la evolución del sistema europeo de Derecho de la Competencia para complementar el tradicional esfuerzo público en la aplicación de dicho derecho con las acciones privadas. Se centra en lo que la literatura económica denomina los efectos paraguas de la colusión.

\section{3. "Efectos paraguas" \\ EN LOS CASOS DE COLUSIÓN}

Los efectos paraguas (umbrella pricing o umbrella effects) tienen lugar cuando los incrementos en el precio de los productos objeto del acuerdo colusorio generan una desviación de la demanda hacia productos sustitutos. Una colusión exitosa es capaz de reducir las cantidades producidas y elevar los precios, lo que lleva a que parte de la demanda por dichos productos se dirija hacia sustitutos que no son objeto del acuerdo o que son producidos por empresas que no forman parte de la colusión.

La demanda incrementada por productos con algún grado de sustituibi-

indemnizaciones. Los comunicados de prensa oficiales de la $\mathrm{CE}$ en sus casos condenatorios hace años incluyen una declaración estandarizada que apunta a ello. Con un número considerable de casos en el ámbito regional y de casos que la FNE archiva, en no pocas ocasiones, por mera priorización de recursos o por carecer de alto impacto, dejando con ello a eventuales víctimas con pocas herramientas o derechamente en la indefensión (presentar de manera directa una demanda ante el TDLC no es opción para cualquier víctima, en los hechos), cabe preguntarse si este es el arreglo institucional que el interés general aconseja mantener. lidad con los productos objeto de la colusión genera una presión al alza en los precios de estos productos.

De este modo, se denominan 'efectos paraguas' los incrementos de precios en productos que no son objeto de la colusión, ni necesariamente producidos por las empresas parte de esta, pero que, frente a los efectos directos de la colusión en los productos objeto de ella, se tornan en sustitutos suficientemente próximos, incrementando su demanda y elevando sus precios.

Los efectos paraguas de la colusión pueden generarse tanto en productos que pertenecen al mismo mercado relevante (por ejemplo, cuando la colusión no involucra a todos los participantes), pero también en productos que pertenecen a algún otro mercado relevante relativamente próximo.

Si bien las causas inmediatas de los efectos paraguas de la colusión son el incremento de la demanda por productos que con la colusión aparecen como sustitutos y la respuesta de los oferentes de dichos productos (esto es, si se comportan como meros tomadores de precios o si por el contrario reaccionan de forma estratégica al incremento de la demanda), desde el punto de vista económico y de la causalidad de hecho, los llamados efectos paraguas son, sin duda, atribuibles a la colusión ${ }^{11}$.

${ }^{11}$ Inderst, Maier-Rigaud \& Schwalbe (2013). Que la determinación y avaluación de los efectos paraguas no siempre se haga en los informes de daños económicos en los casos de colusión tiene relación con las dificultades de su cálculo y con la postura 'conservadora' que suelen seguir estos informes (esto es, hacer la estimación de daños por un mínimo relativamente fácil de calcular, expresando que se dejan partidas fuera, por lo que los daños totales efectivos serían aún mayores). 
Sin embargo, determinar si el deber de los miembros del acuerdo colusorio de reparar los daños derivados de la colusión ha o no de extenderse a los daños por precios más elevados pagados por clientes a empresas que no forman parte del acuerdo colusorio, tratándose de incrementos de precios que no habrían tenido lugar si no es por la colusión ('efectos paraguas' de la colusión), plantea un interesante problema de casualidad jurídica o imputación objetiva y de antijuridicidad de la norma de competencia infringida.

Así fue entendido por la Corte $\mathrm{Su}-$ prema de Austria (Oberster Gerischtshof) en el caso en comento, lo que llevó a dicho tribunal a plantear la siguiente cuestión ante el Tribunal de Justicia de la Unión Europea como petición de decisión prejudicial sobre interpretación del art. 101 del TFUE ${ }^{12}$ :

“¿Debe interpretarse el art. 101 TFUE (...) en el sentido de que cualquier persona tiene derecho a exigir a los participantes en un cártel una indemnización por los daños causados por una empresa ajena al cártel que, aprovechándose de los excesivos precios del mercado, incrementó los precios de sus propios productos más de lo que hubiera

${ }^{12}$ La petición de decisión prejudicial es un procedimiento ante el TJUE que permite a los tribunales superiores de los Estados miembros plantear una consulta al TJUE sobre la interpretación o la validez del derecho de la UE, fundado en lo dispuesto por los artículos 19, apartado 3, letra b), del TFUE y 267 del TFUE. V. TJUE, Recomendaciones a los órganos jurisdiccionales nacionales, relativas al planteamiento de cuestiones prejudiciales, 2012/C 338/01. hecho de no existir el cártel ("um brellapricing"), de manera que el principio de efectividad declarado por el Tribunal de Justicia (...) exige que el Derecho nacional reconozca el derecho a indemnización?"13.

\section{El CASO}

Y EL PROCEDIMIENTO EN CUESTIÓN

El caso que antecede a este procedimiento es la famosa colusión de los ascensores y escaleras mecánicas. Entre los años 1995 y 2004, al menos, las principales empresas europeas del sector celebraron acuerdos para repartirse el mercado de ascensores y escaleras mecánicas en varios Estados miembros de la UE.

En febrero de 2007, la CE impuso a las empresas de los grupos Kone, Otis, Shindler y Thyssen Krupp multas por un monto total de novecientos noventa y dos millones de euros, la más alta impuesta por la CE a esa fecha. Las empresas se coludieron en la asignación de contratos de venta, instalación, mantenimiento y modernización de ascensores y escaleras mecánicas con el fin de congelar las participaciones de mercado y fijar precios en Bélgica, Alemania, Luxemburgo y Holanda. Las empresas también intercambiaron secretos comerciales e información comercialmente sensible en relación con sus ofertas en licitaciones. Las licitaciones de este modo manipuladas incluyeron hospitales, estaciones ferroviarias, centros comerciales y edificios

${ }^{13}$ TJUE (Quinta), 5 de junio de 2014, C-557/

$12, \S 17$. 
de oficinas ${ }^{14}$. La decisión de la CE fue confirmada por el Tribunal General ${ }^{15}$ y los recursos en contra de esta última decisión fueron desestimados por el Tribunal de Justicia en $2013^{16}$.

De modo paralelo, en Austria, el Kartellgericht (Tribunal de Competencia) mediante decisión de 14 de diciembre de 2007 impuso multas a Kone, Otis, Schindlery a otras dos sociedades por prácticas colusorias similares. En el caso austriaco, Thyssen Krupp se liberó de sanciones al haberse acogido al beneficio de clemencia. Esta decisión fue confirmada por la Corte Suprema de Austria en octubre de 2008.

La pretensión indemnizatoria ÖBB", buscaba obtener de estas empresas la reparación de un perjuicio avaluado en cerca de dos millones de euros y se fundaba en el hecho de que adquirió del acuerdo colusorio controvertido, ascensores y escaleras mecánicas a un precio más elevado que el que se habría aplicado de no existir la colusión, debido

${ }^{14}$ Decisión de la CE C(2007) 512 Final de 21 de julio de 2007, asunto COMP/E-1/38.823 - Ascensores y escaleras mecánicas.

${ }^{15}$ Sentencias del TJUE 13 de julio de 2011 en el asunto T-151/07 Kone and Others v Commission; en los asuntos acumulados T-141/07, T-142/07, T-145/07, T-146/07 General Technic Otis and Others v Commission; en el asunto T-138/07 Schindler Holding and Others v Commission; en el asunto T-147/07 (asuntos acumulados T-144/07, T-147/07 T-148/07 T-149/07 T-150/07T-154/07) Thyssen Krupp and Others v Commission

${ }^{16}$ Sentencia del TJUE 24.10.2013 en el asunto C-510/11 P, recurso de Kone; Sentencia del TJUE 18 de julio de 2013 en el caso C-501/11 P, recurso de Schindler; Sentencias del TJUE 15 de junio de 2012 en el caso C-494/11 P, recurso de Otis, y en el caso C-493/11 P, recurso de United Technologies; Thyssen Krupp se desistió de sus recursos ante el TJUE.

a que, a su juicio, esas terceras empresas aprovecharon la existencia de la colusión para fijar sus precios en un mayor nivel.

La demanda de ÖBB fue desestimada en primera instancia, pero acogida en apelación. Conociendo de los recursos en contra de la sentencia de apelación, la Corte Suprema de Austria duda, suspende y solicita una decisión prejudicial al Tribunal de Justicia de la Unión Europea en los términos ya indicados.

\section{LO RESUELTO POR EL TJUE.}

EL INFORME DE LA ABOGADA GENERAL. RECEPCIÓN DE LA DECISIÓN POR LA COMUNIDAD JURÍDICA

La petición de decisión prejudicial ante el TJUE emanada del máximo tribunal austriaco, manifestaba una toma de posición, al menos preliminar. Para este último órgano, la cuestión de si el deber de reparación de los miembros de un acuerdo colusorio debía extenderse o no a indemnizar a clientes de terceras empresas que pagaron a estas precios más elevados que no habrían existido en ausencia de la colusión, era un asunto

i) de competencia del ordenamiento jurídico interno de cada estado miembro-sibien aquí es dónde se centran sus principales dudas que justifican su petición ante el $\mathrm{TJUE}^{17}$,

17 "A causa de la primacía del Derecho de la Unión, la cuestión planteada reviste a su juicio una importancia determinante, debido a la incertidumbre que existe en cuanto a si la exclusión del derecho a indemnización es compatible con el principio de efectividad establecido por el Tribunal de Justicia." TJUE (Quinta), 5 de junio de 2014, C-557/12, §16. 
ii) que el ordenamiento jurídico austriaco responde negativamente de modo categórico, por tratarse de un daño que no satisface las exigencias de una relación de causalidad adecua$\mathrm{da}^{18}$, y que no reviste el carácter de antijurídico desde el punto de vista de la doctrina de la finalidad de la norma ${ }^{19}$.

18 "El órgano jurisdiccional remitente expone que, en virtud del concepto de causalidad adecuada, el autor de un perjuicio debe asumir la reparación de todas las consecuencias, incluidas las fortuitas, cuyo eventual acaecimiento podía anticipar in abstracto, pero no la reparación de las consecuencias atípicas. Según esta jurisprudencia, cuando una empresa ajena a un cártel aprovecha el efecto paraguas, no existe una causalidad adecuada entre el cártel y el perjuicio eventualmente sufrido por el comprador, puesto que se trata de un perjuicio indirecto, un efecto colateral de una decisión independiente que una persona ajena al cártel ha adoptado en función de sus propias consideraciones de gestión. Se considera que el efecto que produce en un competidor la situación del mercado, modelada por los miembros de un cártel, las conclusiones económicas que dicho competidor extrae para su empresa, así como para sus productos, y las decisiones de gestión que adopta en consecuencia, en particular para fijar los precios, son circunstancias en buena medida determinadas por un gran número de factores, que no guardan ninguna relación con ese cártel.” TJUE (Quinta), 5 de junio de 2014, C-557/12, \$14.

19 "En lo que atañe a la cuestión de la antijuridicidad, el Oberster Gerichtshof estima que, según la doctrina relativa a la finalidad protectora de la norma, el hecho de causar un daño patrimonial sólo acarrea una obligación de reparación en el caso de que la irregularidad del daño resulte de la infracción de obligaciones contractuales, de derechos absolutos o de leyes protectoras. La cuestión determinante consiste en dilucidar si la norma infringida por el autor del daño tenía por objeto la protección de los intereses del lesionado. A su entender, no ocurre así en el caso del efecto paraguas sobre los precios ("umbrellapricing"), que no implica ninguna relación de antijuridicidad. Los comportamientos
El TJUE, al resolver, en principio comparte que se trata de una cuestión que ha de ser resuelta por el ordenamiento jurídico interno de cada Estado miembro ${ }^{20}$. Sin embargo, hace valer dos principios de la primacía del Derecho de la Unión que no pueden ser desatendidos por los ordenamientos jurídicos internos. Se trata, en definitiva, de criterios que deben ser satisfechos por

"las normas aplicables a los recursos destinados a garantizar la salvaguardia de los derechos que el efecto directo del Derecho de la Unión confiere a los justiciables".

Dichos principios son

i) el de equivalencia, esto es, que dichas normas

"no deben ser menos favorables que las relativas a recursos similares de naturaleza interna"

en otras jurisdicciones, protegiendo así un mínimo de uni-

ilícitos de los miembros de un cártel perjudican a las personas que adquieren sus productos a los precios artificialmente elevados que ellos aplican. El perjuicio causado por el precio establecido conforme al efecto paraguas solo es un efecto colateral de una decisión independiente que una persona ajena al cártel ha adoptado sobre la base de sus propias consideraciones de gestión". TJUE (Quinta), 5 de junio de 2014, C-557/12, \$15.

20 "Ante la inexistencia de una normativa de la Unión en la materia, corresponde al ordenamiento jurídico interno de cada Estado miembro regular las modalidades de ejercicio del derecho a solicitar la reparación del daño resultante de un acuerdo o práctica prohibidos por el artículo $101 \mathrm{TFUE}$, incluyendo lo relativo a la aplicación del concepto de "relación de causalidad [...]". TJUE (Quinta), 5 de junio de 2014, C-557/12, \$24. 
formidad en la aplicación del Derecho de la Unión y

ii) el de efectividad, esto es, que dichas normas

"no deben hacer prácticamente imposible o excesivamente difícil el ejercicio de los derechos conferidos por el ordenamiento jurídico de la Unión" ${ }^{21}$.

Es sobre la base del principio de efectividad que el TJUE resuelve que vulnera dicho principio una normativa interna que excluye de manera categórica y en todo evento la reparación por los miembros del acuerdo colusorio de los daños causados a las víctimas por el "efecto paraguas" de la colusión. Por el contrario, se cumple con dicho principio cuando la normativa interna admite tal reparación a las víctimas, particularmente cuando

"según las circunstancias del caso $y$, en particular, conforme a las especificidades del mercado en cuestión, dicho cártel podía tener como consecuencia que terceras partes, actuando de manera autónoma, aplicaran precios aprovechando la concertación, y que tales circunstancias y especificidades no podían ser ignoradas por los miembros del cártel”,

cuestiones a ser apreciadas por el órgano jurisdiccional que conoce del caso $^{22}$. En este sentido, y luego de des$12, \S 25$

${ }^{21}$ TJUE (Quinta), 5 de junio de 2014, C-557/

${ }^{22} \mathrm{El}$ núcleo de lo resuelto se extrae bien de la lectura de los párrafos $§ 32$-\$34 de la decisión del TJUE: estimar las alegaciones de que la reparación de estos daños tendría un carácter punitivo por no tener el perjui-

"Es cierto que [...] corresponde en principio al ordenamiento jurídico interno de cada Estado miembro determinar las normas relativas a la aplicación del concepto 'relación de causalidad'. Sin embargo, de la jurisprudencia del Tribunal de Justicia, [...] resulta que estas normas nacionales deben garantizar la plena efectividad del derecho de la competencia de la Unión [...]. Así, estas normas deben tener en cuenta específicamente el objetivo perseguido por el artículo 101 TFUE, que pretende garantizar el mantenimiento de una competencia efectiva y no falseada en el mercado interior y, de este modo,asegurar que los precios se fijan en función del juego de la libre competencia. Estas son las circunstancias en las que el Tribunal de Justicia ha declarado [...], que las normas nacionales deben reconocer a cualquier persona el derecho a solicitar una reparación del perjuicio sufrido”. \$32

"Pues bien, la plena efectividad del artículo 101 TFUE resultaría menoscabada si el derecho de cualquier persona a solicitar la reparación del perjuicio sufrido quedara subordinado por el Derecho nacional, de manera categórica e independientemente de las circunstancias específicas del caso, a la existencia de una relación de causalidad directa, excluyendo tal derecho debido a que la persona en cuestión ha tenido vínculos contractuales, no con un miembro del cártel, sino con una empresa no participante en éste, cuya política de precios, no obstante, es una consecuencia del cártel que ha contribuido a falsear los mecanismos de formación de los precios que rigen en los mercados competitivos”. \$33

"Por consiguiente, la víctima de un efecto paraguas sobre los precios ("umbrellapricing") puede obtener de los miembros de un cártel la reparación del daño sufrido, aun cuando no haya tenido vínculos contractuales con ellos, en la medida en que se acredite que, según las circunstancias del caso y, en particular, conforme a las especificidades del mercado en cuestión, dicho cártel podía tener como consecuencia que terceras partes, actuando de manera autónoma, aplicaran precios aprovechando la concertación, y que tales circunstancias y especificidades no podían ser ignoradas por los miembros del cártel. Corresponde al órgano jurisdiccional remitente comprobar si se satisfacen estas condiciones”. \$34 
cio de las víctimas la contrapartida de un lucro de las empresas coludidas ${ }^{23}$ y de que dicha reparación debilitaría el programa europeo de clemencia disuadiendo la colaboración de las empresas mediante su participación en este programa ${ }^{24}$, el TJUE concluye:

"El artículo 101 TFUE debeinterpretarse en el sentido de que se opone a una interpretación y a una aplicación del Derecho interno de un Estado miembro consistente en excluir de manera categórica, por motivos jurídicos, que empresas participantes en un cártel respondan civilmente por los daños resultantes de los precios que una empresa no participante en dicho cártel ha fijado, teniendo en cuenta la actuación de dicho cártel, en un nivel más elevado que el que habría aplicado de no existir el cártel" 25 .

Cabe señalar que el informe de conclusiones de la abogada general Juliane

23 "Procede señalar que las normas en materia de responsabilidad extracontractual no establecen que el importe de un perjuicio indemnizable dependa del beneficio obtenido por quien haya cometido el acto que causó el daño." TJUE (Quinta), 5 de junio de 2014, C-557/12, \$35

${ }_{24}$ "El programa de clemencia es un programa establecido por la Comisión, [...] que no tiene carácter legislativo y no es imperativa para los Estados miembros [...]. Por consiguiente, dicho programa de clemencia no puede privar a los individuos del derecho a obtener una indemnización, ante los órganos jurisdiccionales nacionales, del daño sufrido a causa de una infracción del artículo 101 TFUE”. TJUE (Quinta), 5 de junio de 2014, C-557/12, \$36

${ }^{25}$ TJUE (Quinta), 5 de junio de 2014, C-557/ $12, \S 37$
Kokott ${ }^{26}$ había ido más allá, siendo aún más explícito sobre el carácter instrumental de las normas civiles internas sobre reparación de daños al servicio del derecho de la competencia de la Unión ${ }^{27}$, llegando, incluso, a proponer, con más detalle, criterios causalidad suficientemente directa de los daños por 'efectos paraguas' ${ }^{28}$. En este sentido, se

${ }^{26}$ Кокотт (2014) Los ocho abogados generales que se desempeñan en el TJUE tienen la mismas calificaciones que los jueces de dicha Corte y su función es la de presentar un informe imparcial, independiente y razonado en los casos de que conoce el TJUE. Las conclusiones del abogado general son consignadas en un documento estructurado de modo similar a una resolución judicial, pero no son de ninguna manera vinculantes para el TJUE al emitir su sentencia, por lo que pueden existir diferencias entre uno y otro documento. El sistema de abogados generales proviene del sistema judicial francés.

${ }^{27}$ Кокотт (2014) §28: "La problemática de la responsabilidad civil de los participantes en el cártel por los efectos paraguas sobre los precios es una cuestión de Derecho de la Unión. En efecto, si se trata de determinar si los miembros de un cártel deben reparar los daños ocasionados por los efectos paraguas, la cuestión no se refiere sólo a las modalidades del ejercicio y cálculo de las acciones indemnizatorias y a la práctica de la prueba ante los órganos jurisdiccionales nacionales (es decir, el 'cómo' de la indemnización), sino que en el centro de interés se sitúa la cuestión, mucho más fundamental, de si puede exigirse responsabilidad civil a los participantes en el cártel por ese tipo de daños y si pueden ser demandados por personas que no fueron compradores suyos, ni directa ni indirectamente (es decir, si procede la indemnización). Esta cuestión no se puede dejar únicamente a los ordenamientos jurídicos de los Estados miembros".

${ }^{28}$ Кокотт (2014) §34-\$83. Por su profundidad y extensión, de entre los diversos documentos analizados, aquí parece encontrarse el análisis más interesante, lo que amerita una breve referencia. Luego de descartar que lo que se exige aquí sea una causalidad exclusiva y de descartar también que la libertad de las terceras empresas no coludidas obligue a tener por interrumpido el vínculo causal entre los daños por los precios 
percibe un sutil ejercicio de autocontención de parte del TJUE en relación con el informe de la abogado general.

cobrados por estas y la acción de las empresas coludidas §36-\$39, el informe expresa: "Con el criterio de la causalidad suficientemente directa se pretende asegurar, por un lado y en lo que al contenido se refiere, que una persona sólo deba responder, como consecuencia de su comportamiento ilícito, por los daños cuya materialización razonablemente pudiera prever [...], y, por otro, que una persona sólo deba reparar los daños cuyo resarcimiento sea conforme con los objetivos de la norma por él vulnerada [...]" §40. Más tarde concluirá que la obligación de las empresas coludidas de reparar los daños por los efectos paraguas satisface ambos criterios $\$ 83$.

Respecto del primer punto, expresa: "Son previsibles (o producidos por una causalidad adecuada) todos los daños con cuya materialización razonablemente deban contar los participantes en el cártel según la experiencia general,en contraposición a los daños debidos a un encadenamiento totalmente extraordinario de circunstancias y, por tanto, a un desarrollo causal atípico" \$42. Concluirá luego: "los daños causados por los efectos paraguas sobre los precios no son unos daños cuya aparición sea siempre atípica o imprevisible para los participantes en el cártel. Sería incompatible con la eficacia práctica del [artículo 101 del TFUE] excluir de antemano la reparación de dichos daños remitiéndose a una concepción relativamente estricta del criterio de la causalidad adecuada" \$52. Para concluir sostiene, en síntesis, que (i) es normal y previsible que empresas ajenas al cartel fijen sus precios atendiendo al comportamiento de los miembros del cartel en el mercado, sea que conozcan o no de la colusión $\$ 46$; (ii) mientras mayor parte del mercado relevante sea cubierto por la colusión, más influencia tendrá esta en los precios del mercado en su conjunto y menor será la capacidad de empresas ajenas a la colusión de influir significativamente en los precios $\$ 47$; (iii) no puede asumirse que la colusión en mercados poco homogéneos o poco transparentes no genere efectos paraguas $\$ 48-\$ 49$; (iv) incluso la determinación de precios por un desafiante efectivo del cartel estará influida por los precios del cartel §50; (v) las empresas del cartel tienen interés y cuentan con que las ajenas al cartel las sigan, esto es, cuentan con que los efectos paraguas se produzcan para mayor eficacia del acuerdo colusorio $\$ 51$.
No obstante, no todos los miembros de la comunidad jurídica europea parecen haberlo entendido de igual modo

Respecto del segundo punto, el de la conformidad con la norma vulnerada, expresa que es difícil sostener que el reconocimiento de una responsabilidad civil de los participantes en el cártel por los daños causados por los efectos paraguas sobre los precios sea incompatible con los objetivos de creación y mantenimiento de un sistema de competencia no falseada en el mercado interior europeo, objetivos que son servidos tanto por mecanismos privados como públicos de aplicación del Derecho de la Competencia. Desarrolla luego cómo semejante obligación reparatoria se inserta en el sistema de aplicación de las normas de competencia (a) y cómo semejante obligación reparatoria es idónea para subsanar las consecuencias negativas que la colusión tiene para los consumidores (b).

Sobre el punto (a) expresa: (i) que al igual que respecto de las demás consecuencias de las prácticas anticompetitivas, la eficacia del derecho encargado de reprimirlas descansa en mecanismos públicos y privados, descansar solo en los primeros para los efectos paraguas debilitaría de forma grave la vigencia efectiva de las normas de competencia $\$ 59-\$ 60$; (ii) los incentivos que genera la obligación reparatoria por los daños de los efectos paraguas no ponen en riesgo el programa de clemencia y complementan de manera adecuada el conjunto de consecuencias negativas a que se exponen los partícipes de una colusión §61-\$65; (iii) la referida obligación reparatoria no puede ser considerada un costo adicional que disuada la participación de empresas en los mercados, ya que la efectividad del derecho que asegura como un valor en sí mismo una competencia sin falseamientos apunta justo a que se haga realidad una economía social de mercado muy competitiva $§ 66$ - 668 ; (iv) la supuesta sobrecarga de los tribunales civiles por tener que atender estas cuestiones no es motivo para denegar categóricamente la reparación de este tipo de daños, ya que las dificultades probatorias ante tribunales civiles son suficiente válvula de control §69-§70.

Sobre (b), esto es, la idoneidad del remedio para subsanar las consecuencias negativas de la colusión, (i) parte por identificar la siguiente función de la responsabilidad civil en materia infraccional: "dicha función consiste en subsanar las consecuencias negativas de las infracciones 
y la recepción de la decisión del TJUE no ha sido uniformemente favorable. No pocos han visto aquí una intromi-

cometidas, y precisamente a tal fin sirve también la obligación de las empresas del cártel de reparar los daños causados a otros con sus prácticas contrarias a la competencia. Al mismo tiempo, la posibilidad de reclamar la reparación fortalece la confianza en las normas de competencia de la Unión Europea y contribuye sustancialmente a su aplicación efectiva" \$70; (ii) luego, refuta la defensa de que la intención de las empresas coludidas no se extendía a los sobreprecios pagados por clientes de empresas ajenas al cartel, en los siguientes términos: "La apreciación de la causalidad entre un cártel y determinados tipos de daños que pueden haber sufrido los operadores económicos se basa en criterios puramente objetivos. Desde un punto de vista subjetivo, la responsabilidad civil puede depender de que los participantes en el cártel hayan incumplido de forma dolosa o negligente las normas de competencia de los Tratados. Pero es irrelevante si, además, los participantes en el cártel causaron dolosa o negligentemente los daños concretos materializados. Tal exigencia de culpabilidad sería incompatible con los principios generales del Derecho civil y dificultaría sobremanera la aplicación práctica de las normas de competencia” \$74; con todo, agrega a continuación que, los daños ocasionados por efectos paraguas son subjetivamente imputables a los miembros del cartel a título de "al menos, negligencia, pero en algunos casos incluso dolo eventual” $§ 75$; (iii) descarta que el derecho a indemnización tenga por función anular las ganancias ilegítimas de los miembros del cartel: "el derecho a reparación se distingue esencialmente del derecho a la entrega del enriquecimiento injusto. Con la indemnización no se pretende primordialmente quitarle al causante aquello que tenga en exceso, sino conceder al perjudicado una satisfacción por el perjuicio sufrido a causa del comportamiento ilícito del causante. Es perfectamente conforme con esa función extender la responsabilidad civil de los participantes en el cártel a los daños causados por los efectos paraguas sobre los precios" §78; (iv) la obligación de las empresas coludidas de reparar los daños por los efectos paraguas no constituye una indemnización de carácter sancionatorio, toda vez que se limita a la reparación del daño causado sin obligar a ninguna sobrecompensación sobre dicho daño \$79-\$81. sión indebida, por vía del ejercicio de jurisdicción por el TJUE en asuntos de competencia de los ordenamientos internos de cada Estado miembro, reparto de competencias que habría quedado asegurado, por ejemplo, por la exclusión del texto de la directiva de Daños y Perjuicios por Infracciones a la Competencia de toda referencia a la relación de causalidad. La primacía del derecho de la UE y el principio de efectividad pudieron más en esta ocasión.

\section{Resumen y Algunas reflexiones PARA FUturos Desarrollos EN CHIle}

El TJUE ha declarado en sus últimas decisiones que es contraria al principio de efectividad del derecho de la competencia de la UE la normativa interna de un Estado miembro que excluye de manera categórica el deber de las empresas coludidas de reparar los daños por los 'efectos paraguas', que son los incrementos de precios soportados por clientes de terceras empresas no partícipes en la colusión, que no se habrían producido en ausencia de esta.

Se trata de daños que, teóricamente, satisfacen tanto el requisito de causalidad jurídica, en su relación con las conductas de las empresas coludidas como el requisito de antijuridicidad, en atención a los objetivos del derecho de la competencia. Los antecedentes del caso comentado brindan un buen cúmulo de argumentos para así sostenerlo. Las dificultades probatorias a superar por las víctimas que persigan la reparación de este tipo de daño constituyen una válvula suficiente que hace innecesario descartar a priori y de modo categórico la obligación de repararlos. 
En el caso comentado, el impulso en Europa a los mecanismos privados de aplicación del derecho de la competencia, y un proyecto de reforma legal en discusión en Chile, parecen motivos suficientes para plantear algunas interrogantes.

Quizá una primera cuestión es si se hace o no necesaria una revisión a la actual conjugación entre mecanismos públicos y privados para la aplicación del derecho de la competencia en Chile, con miras a fortalecer los mecanismos privados. Esto es, que frente a casos razonables, los particulares tengan incentivos suficientes para actuar como 'procuradores privados del interés público'. Tal como sostiene la abogada general Juliane Kokott en sus conclusiones: sin esclarecer de modo previo cuál es la causa preponderante de la mayor efectividad de la acción pública ${ }^{31}$. Una metodología con ciertas correcciones ${ }^{32}$ debiera llevar, a lo menos, a matizar una tesis semejante. Si se hace o no necesaria una revisión a la actual conjugación entre mecanismos públicos y privados de aplicación, es una primera cuestión que debe ser resuelta principalmente por los encargados del diseño institucional de la política de competencia.

Una segunda interrogante que surge del estudio del caso, de carácter conceptual y vinculada a la anterior, es si los mecanismos de reparación de daños a las víctimas de una infracción a la libre competencia son una cuestión de mayor protagonismo, a través de litigios, por parte de los privados".

${ }^{31}$ Gonzalez, Micco \& Caicha (2013), p. 67. Los autores identifican tres razones posibles para la superior efectividad de la acción pública: mayor capacidad técnica de la FNE que la de privados, utilización estratégica de los litigios por privados y, facultades de investigación de la agencia pública de las cuales carecen los particulares; pero afirman no poder identificar la causa preponderante de dicha superioridad, con la información disponible.

${ }^{32}$ Creemos, primero, que de modo comple-

Dado el estado actual de los mecanismos privados de aplicación del derecho de la competencia en Chile, resultan llamativas las conclusiones de un reciente estudio que, en la alternativa de fortalecer los mecanismos públicos vs. los mecanismos privados, defienda tan de manera abierta la opción de reforzar los públicos ${ }^{30}$, particularmente,

${ }^{29}$ Кокотт (2014) §60.

${ }^{30}$ Gonzalez, Micco \& Caicha (2013) pp. 6768: "Los resultados obtenidos sugieren que para lograr una mayor efectividad de la política de competencia sería preferible un fortalecimiento de la persecución pública en vez de inducir un mentario a comparar la eficacia entre el public y private enforcement con los incentivos que hoy tienen los privados para accionar en Chile (bajos castigos por demandas infundadas, no muy elevados premios por demandas debidamente fundadas, pocas herramientas procesales, etc.), debe considerarse como contrafactual (alternativa hipotética o referencia a la experiencia extranjera) cómo se daría dicha relación con instrumentos de aplicación -tanto públicos como privadosmejor diseñados. Por otra parte, una muestra representativa para estos fines debiese incluir no sólo los casos que ha conocido el TDLC sino además el gran número de causas archivadas por la FNE, en no pocas oportunidades, por criterios de priorización y análisis costo-beneficio e impacto de la agencia administrativa, ajenos al interés general de aplicación de la ley. 
responsabilidad civil o una cuestión de derecho de la libre competencia. Esto es, en otros términos, chasta qué punto las normas de responsabilidad civil han de servir de forma complementaria a la eficacia y efectividad del derecho de la competencia (para el cual el deber de reparación de daños cumple no solo la clásica función compensatoria sino, además, un papel de disuasión de conductas anticompetitivas) y, en este sentido, asumir un grado de instrumentalización? El enfoque de justicia correctiva para el Derecho Civil que inspira a parte relevante de la doctrina nacional se opondría a una instrumentalización semejante. En esta concepción, la responsabilidad civil extracontractual obedece a conceptos de Derecho Privado, propios, autónomos e independientes, que no debieran ser contaminados por concepciones instrumentales de Derecho Público ${ }^{33}$; solo cabría atribuir un papel modesto a la responsabilidad civil como mecanismo de aplicación del derecho de la libre competencia ${ }^{34}$. A diferencia de la primera interrogante, esta segunda es una cuestión que, en ausencia de solución legislativa, debe ser resuelta preferentemente por los jueces que ejercen jurisdicción en materia de daños e indemnizaciones civiles.

Quizá lo razonable sea no aferrarse a un enfoque único, ni responder en términos generales, sino identificar y defender que cada una de las materias antimonopolios, esto es, colusión, abusos de posición dominante y operaciones de concentración justifica reglas diferentes y amerita, por tanto, respues-

\footnotetext{
${ }^{33}$ Barros (2008).

${ }^{34}$ Banfi (2014); Banfi (2013).
}

tas bien diferenciadas a las cuestiones anteriores.

Y en materia de colusión entre competidores, hoy parecen existir ciertos consensos en Chile. Estos son, entre otros, que a pesar de tratarse del ilícito de mayor gravedad de entre las infracciones a la libre competencia ${ }^{35}$, la capacidad de disuasión del sistema sigue siendo baja en relación con economías de mercado con instituciones maduras $^{36}$ y que el beneficiado con exención o reducción de multas no se encuentra de forma suficiente protegido lo que disminuye los incentivos para autodelatarse ${ }^{37}$. Un mejor diseño

${ }^{35}$ La particularidad gravedad de la colusión entre competidores viene siendo sostenida reiteradamente por la jurisprudencia desde que la CS estableciera a fines de 2010 que: "La colusión constituye de todas las conductas atentatorias contra la libre competencia la más reprochable, la más grave, ya que importa la coordinación del comportamiento de las empresas. El resultado probable de tal coordinación es la subida de los precios, la restricción de la producción y con ello el aumento de los beneficios que obtienen los participantes". CS, 29 de diciembre de 2010, rol 1746-2010 (cons. $12^{\circ}$ ), recaída en reclamaciones contra TDLC, 7 de enero de 2010, sentencia $N^{\circ} 94$ / 2010 caso Transportistas Osorno.

${ }^{36}$ De allí la propuesta de modificar el tope máximo fijo de multas que establece la ley (art. 26 letra c) DL No 211), y sustituirlo por un tope proporcional al tamaño de la empresa, medido por volúmenes de ingresos. En este sentido, entre otros, Informe Comisión Asesora Presidencial PARA LA DEFENSA DE LA LIBRE COMPETENCIA(2012); Informe Grupo Res Publica Chile (2013), Informe Horizontal (2013).

${ }^{37}$ De allí la propuesta de excluir a quien ha obtenido los beneficios de exención o reducción de multas del art. 39 bis DL No 211 del riesgo de persecución penal. En este sentido, entre otros, Informe Comisión Asesora Presidencial para LA DEFENSA DE LA LIBRE COMPETENCIA(2012), Informe Grupo Res Publica Chile (2013), INFORME HORIZONTAL (2013). 
de la reparación de daños a las víctimas de la colusión entre competidores puede contribuir a proveer esta necesaria asimetría:

a) mejor protección para la empresa coludida que por ser primera en autodelatarse obtiene el beneficio de exención de multas y

b) mayor poder de disuasión del sistema respecto de las demás.

En cuanto al punto (a) la experiencia comparada y un antecedente nacional ${ }^{38}$ aconsejan una carga reparatoria más benevolente para el primer autodelator en relación con los demás copartícipes de la colusión. Excluir a su respecto la solidaridad y hacerlo responder solo de manera mancomunada ya sería algo. Pero además, junto

${ }^{38}$ En Estados Unidos, la reforma legal conocida como ACPERA del año 2004 dispuso para el beneficiado de amnistía una reducción de su responsabilidad civil a daños simplemente reparatorios (no triplicados) y en forma mancomunada -no solidaria. En Chile, el Mensaje con que fue despachado el proyecto que terminó siendo aprobado como ley $\mathrm{N}^{\mathrm{o}}$ 20.361/2009 agregaba un inciso final al artículo $30 \mathrm{DL} \mathrm{N}^{\circ} 211$, relativo a la determinación de la indemnización de perjuicios por el tribunal civil, con el objetivo de excluir de la solidaridad prevista en el art. 2317 del $C C$ al beneficiado por el TDLC que hubiese declarado o aportado antecedentes eficaces para la investigación o comprobación del ilícito, pero sin afectar el derecho del perjudicado a ser reparado íntegramente de los daños sufridos. Esto, en definitiva, no fue recogido por el texto aprobado de la ley. El dilema entre, por una parte, la reserva y protección de la información aportada por la empresa beneficiada de amnistía o clemencia en sede administrativa y, por otra parte, su necesaria divulgación para que las víctimas puedan obtener, en sede civil, la indemnización de sus daños es una de las principales cuestiones que enfrentan hoy los sistemas de delación compensada en el ámbito comparado. con el alcance limitado a su cuota en el daño, puede establecerse que responderá sólo en subsidio del no pago de la obligación solidaria y principal de los demás copartícipes en la colusión, y también o alternativamente, excluirse de forma explícita a su respecto la obligación de reparar ciertas categorías de daños (por ejemplo, los causados por la colusión a los clientes de otros copartícipes en la misma, a los compradores indirectos, a los clientes de empresas ajenas a la colusión por los efectos paraguas). En caso de que la víctima de la colusión sea una entidad fiscal, podría, incluso, irse más allá, liberando al primer autodelator de toda obligación de responder o, bien, mantener el criterio indicado de responder mancomunadamente y solo en subsidio de la responsabilidad principal de los demás copartícipes.

En cuanto al punto (b) debiera hacerse más expedita la declaración y pago de los daños e indemnizaciones civiles por los copartícipes en casos de colusión. Atribuir al mismo TDLC, en procedimiento separado, el conocimiento de las acciones que persiguen esta responsabilidad, es una idea que debiera considerarse. De la primera instancia podría conocer uno de sus ministros como tribunal unipersonal (debiendo definirse si es aconsejable o no que lo sea alguno de los ministros que integró el TDLC para declarar la existencia y condenar el respectivo caso de colusión). De la segunda instancia, podrían conocer ya sea el TDLC en sala integrada con exclusión del ministro que obró como juez de primera instancia o, bien, la Corte de Apelaciones de Santiago. La Corte Suprema conocería, al igual que hoy, de los recursos de 
casación que se interponga contra la sentencia de segunda instancia. Otras modificaciones, aun más opinables, podrían ameritar alguna reflexión y análisis, tales como el establecimiento de daños punitivos ${ }^{39}$, acciones colectivas con menores requisitos que las vigentes en la LPC, la obligación de garantizar mediante consignación un monto razonable para el pago de daños en distintas instancias procesales (por ejemplo, ante la FNE previo a otorgar el beneficio de reducción de multas a quienes no son el primer copartícipe en autodelatarse, o ante el TDLC previo a proveer la reclamación de la sentencia del TDLC para ante la CS). Adicionalmente, para incrementar no

${ }^{39}$ Es un centro de pensamiento que se autodefine como de centro derecha liberal el que ha recientemente promovido tanto la introducción de daños punitivos: "Quienes determinen las compensaciones debiesen ser las instituciones que cuenten con la capacidad técnica para relacionar éstas con el daño infringido a los afectados. Las compensaciones debiesen ser tres veces la pérdida social por la conducta sancionada, con la finalidad adicional de incentivar a los afectados a emprender acciones legales para solicitar compensación" (sic); así como el conocimiento de las indemnizaciones por parte del TDLC: "En su carácter de tribunal especializado, y a fin de lograr una mayor economía procesal y eficacia, pareciera conveniente que la indemnización de daños a terceros por infracción a la ley de libre competencia sea de competencia del TDLC, siendo visto en forma conjunta por la FNE. El TDLC será el que deba cuantificar los daños y establecer la indemnización. Igualmente, se debe buscar incentivar este tipo de acciones por parte de los consumidores". Alternativamente, proponen facultar al SERNAC, con mayores recursos y autonomía para determinar de forma directa los daños. Informe Horizontal (2013), p. 36. Estimamos que es una discusión que debe acotarse a casos de colusión y, eventualmente, sólo a casos de colusión en mercados minoristas (esto es, con consumidores finales afectados). solo la onerosidad de las consecuencias pecuniarias para los copartícipes en la colusión sino, además, la probabilidad de detección de la misma, debiera evaluarse la introducción, con una cuidadosa reglamentación, del instituto procesal estadounidense del discovery ${ }^{40}$, previendo, a la vez, sanciones severas a la utilización abusiva del mismo y, en la misma línea, examinarse la experiencia extranjera de algunas agencias en el pago de recompensas por información sustantiva de casos de colusión ${ }^{41}$ e institutos como las acciones quitam ${ }^{42}$.

La reforma legal a que dé lugar el proyecto en discusión, tanto por lo que diga como por lo que omita, brindará las principales respuestas a estas cuestiones para los próximos años, indicará cuán asimétrico será el régimen de responsabilidad civil del primer autodelator en relación con el régimen para los demás copartícipes en la colusión y, en definitiva, será la guía sobre cómo se

${ }^{40} \mathrm{El}$ instituto procesal del discovery consiste en la divulgación forzada, a requerimiento de parte, de la información requerida para el litigio. Implica exhibición de documentos, declaraciones, testimonios, y discusiones sobre admisibilidad y otras diligencias probatorias a producir. Para una presentación esquemática de cómo ha operado el instituto en casos antimonopolios, MARTIN (2004)

${ }^{41}$ Es lo que han implementado agencias de competencia como la de Corea y la de Reino Unido.

${ }^{42}$ Las acciones quitam (del latín quitam pro domino regequam pro se ipso in hac parte sequitur - "quien demanda en estos autos tanto por el Rey como por sí mismo") tienen aplicación cuando la víctima de la colusión es una entidad del gobierno federal o estadual. Estas acciones, reconocidas en la legislación, permiten a un particular que ha aportado información sustantiva en un caso de defraudación fiscal, obtener parte de las restituciones obtenidas por el fisco sobre la base de la información aportada. 
conjugarán hacia futuro los mecanismos públicos y privados en la aplicación del derecho de la competencia en Chile.

\section{BiBLIOGRAFÍA ${ }^{43}$}

Araya, Fernando. (2005). "Daño anticompetitivo y daño indemnizable: Un ensayo de confrontación". Revista Chilena de Derecho Privado. $\mathrm{N}^{\circ} 4$. Santiago. Julio.

Araya, Fernando. (2003). La relación de causalidad en la responsabilidad civil. Santiago: LexisNexis-Fundación Fernando Fueyo.

BAnfi, Cristián. (2014). "Acerca de la imputación de responsabilidad civil por ilícitos anticompetitivos entre rivales en Chile". Revista Chilena de Derecho. Vol. 41. $\mathrm{N}^{\circ}$ 1. Santiago.

Banfi, Cristián. (2013). "La responsabilidad civil como forma de aplicación privada del derecho de la competencia”. Revista Chilena de Derecho Privado. No 21. Santiago. Diciembre.

Barros, Enrique (2008). "La responsabilidad civil como derecho privado". Estudios Públicos. Vol. 112. Santiago.

Crane, Daniel. (2010) "Optimizing Private Antitrust Enforfcement". Vanderbilt Law Review. Vol. 63, No 2. http://repository.law.umich.edu/ cgi/viewcontent.cgi? article $=1129 \&$ context $=$ articles

Davis, Joshua \& Robert LANDE (2013). "Defying Conventional Wisdom: The Case forPrivate Antitrust Enforcement". Georgia Law Review. Vol. 48. $\mathrm{N}^{\mathrm{o}} 1$. Georgia.

${ }^{43}$ Las visitas a los sitios URL de internet indicados en nota al pie y en la bibliografía se hicieron por última vez el 10 de octubre de 2014 .
Gonzalez, Aldo, Alejandro Micco \& Constanza CAicha (2013). "El impacto de la persecución pública en los juicios de libre competencia en Chile”. Estudios Púbicos, vol. 132. Santiago.

INDERST, Roran, Frank MAIER-RigaUd \& Ulrich SchWALBE (2013). "Umbrella Effects". IESEG Working Paper Series 2013-ECO-17.

Figueroa, Nicolás \&Andrea Repetto (2013). "Capítulo VI. Más competencia y protección efectiva de los consumidores". Andrea Plet y Pilar de Aguirre. Informe Grupo Res Publica Chile. Santiago.

Medina, Fernando \& Pablo Paredes (2013). "Competencia en el mercado chileno. Institucionalidad de la Libre Competencia". Informe Horizontal. Disponible en www.horizontalchile. cl/wp-content/uploads/2013/11/ Horizontal_Competencia-en-elmercado-chileno-octubre-2013.pdf

Kокотт Juliane (2014). "Conclusiones de la Abogado General Sra. Juliane Kokott presentadas el 30 de enero de 2014".

LEWIN, Nicolás (2011). "Indemnización de perjuicios por atentados a la libre competencia: el daño anticompetitivo, su relación con el daño civil y la determinación de los perjuicios". Anales de Derecho UC, No 2. Santiago.

Martin, James Robertson (2004). "Puttingthe Case Together: Organizing and Maximizing Discovery in Civil Antitrust Cases",

MonTt, Paulo \& Benjamin Mordoj (2010). "Chapter 3. Chile". The Private Competition Enforcement Review. Third Edition. Gotts, I.K.

Rosende, Francisco et al. (2012). Informe Comisión Asesora Presidencial para la de- 
fensa de la libre competencia. Disponible en www.economia.gob.cl/wp-con tent/uploads/2012/07/INFORME-
FINAL-ENTREGADO-A-PDTEPINERA-13-07-12.pdf

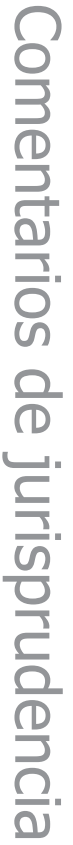

441 